\title{
A PRODUÇÃO DE UVA ORGÂNICA NO ESTADO DO RIO GRANDE DO SUL: AS EXPERIẾNCIAS DOS AGRICULTORES FAMILIARES DE COTIPORÃ E DOM PEDRITO
}

\author{
The production of organic grape in the state of the Rio Grande do Sul: the experiences of the
} family agriculturists of Cotiporã and Dom Pedrito

\author{
Vanessa Manfio* \\ Vinício Luís Pierozan ${ }^{* *}$ \\ Rosa Maria Vieira Medeiros ${ }^{* * *}$ \\ *Doutora em Geografia e Pesquisadora do Núcleo de Estudos Agrários da UFRGS - vamanfio@hotmail.com \\ ${ }^{* *}$ Mestre em Geografia pela UFRGS - vpierozan@hotmail.com \\ ***Professora Doutora do Departamento de Geografia da UFRGS -rmvmedeiros@ufrgs.br
}

Recebido em 01/04/2019. Aceito para publicação em 15/04/2019.

Versão online publicada em 26/04/2019(http://seer.ufrgs.br/paraonde)

\begin{abstract}
Resumo: 0 presente trabalho possui como objetivo geral discutir e analisar a respeito da agricultura familiar, voltada para produção de uva orgânica. A área de estudo envolve dois municípios distintos socialmente e economicamente, Cotiporã e Dom Pedrito, localizados no estado do Rio Grande do Sul. Em nossa análise utilizamos a abordagem qualitativa e como recursos metodológicos organizamos a pesquisa em duas partes: revisão de literatura em relação ao tema proposto e trabalho de campo. 0 texto do trabalho encontra-se estruturado em três partes que irão conduzir as considerações: primeira parte, apresenta uma discussão sobre agricultura familiar e vitivinicultura, a segunda, uma abordagem sobre a vitivinicultura familiar de Cotiporã e na sequência a análise sobre a vitivinicultura desenvolvida em pequenas propriedades rurais no interior do município de Dom Pedrito.
\end{abstract}

Palavras-chave:Agricultura familiar; Uva orgânica; Cotiporã; Dom Pedrito.

\begin{abstract}
The present work presents as a general objective to discuss and analyze about family farming, aimed at producing organic grape. The area of study involves two distinct municipalities socially and economically, Cotiporã and Dom Pedrito, located in the state of Rio Grande do Sul. In our analysis we use the qualitative approach and how methodological resources organize the research in two parts: literature review in relation to the proposed theme and fieldwork. The text of the work is structured in three parts that will lead to the considerations: first part, it presents a discussion on family farming and viticulture, the second, an approach to the viticultural family of Cotiporã and following the analysis on the viticulture developed in small rural properties within the municipality of Dom Pedrito.
\end{abstract}

Key-words: Family farming; Organic grape; Cotiporã; Dom Pedrito.

\section{Introdução}

A agricultura familiar possui algumas características particulares no que se refere ao desenvolvimento rural. Emprega muitas pessoas, gera renda, proporciona um estilo de vida, produção de alimentos e também vem estimulando o desenvolvimento de novas atividades econômicas junto ao espaço rural como, por exemplo, a implantação de agroindústrias, o turismo rural e a produção de alimentos orgânicos. Atualmente vem crescendo significativamente no Brasil, o número de unidades de produção agrícola, que realizam o cultivo de alimentos orgânicos, bem como também, verifica-se um aumento significativo da demanda por esse tipo de produto, que se diferencia dos demais amplamente ofertados no mercado.

O Rio Grande do Sul possui agricultores familiares inseridos dentro da cadeia produtiva da uva e 
do vinho, localizados principalmente na região da Serra Gaúcha, onde a produção de uva é expressiva e representa o maior polo vitivinícola do Brasil. A Federação das Cooperativas Vinícolas do Rio Grande do Sul (FECOVINHO) representa institucionalmente somente na região serrana do Estado mais de 4.000 famílias de agricultores associadas a 6 Cooperativas Vitivinícolas, que juntas são responsáveis, por aproximadamente $27 \%$ da uva cultivada no Rio Grande do Sul (FECOVINHO, 2019, on-line).

No entanto, agricultores familiares de outras regiões do estado também estão investindo na viticultura, embora em sua fase inicial, ela seja utilizada apenas como atividade que gera um complemento de renda da propriedade e não a atividade agrícola principal, como acontece em muitas propriedades agrícolas familiares localizadas na Serra Gaúcha.

Diante disso, o presente artigo busca discutir a respeito da agricultura familiar, voltada para produção de uva orgânica. Para isto, analisou-se dois municípios distintos socialmentee economicamente: Cotiporã e Dom Pedrito (Mapa 1). 0 primeiro localiza-se na região Nordeste RioGrandense (IBGE, 2008) conhecida como Serra Gaúcha, berço da colonização italiana no estado do Rio Grande do Sul. Em contrapartida, o segundo, faz parte da Mesorregião Geográfica Sudoeste RioGrandense (IBGE, 2008) conhecida como Campanha Gaúcha, espaço identitário e representativo da cultura gaúcha.

Para alcançar os objetivos propostos no estudo utilizou-se a abordagem qualitativa e os recursos metodológicos, tais quais: revisão de literatura, trabalho de campo, aplicação de entrevistas semiestruturadas e conversas informais. 0 artigo encontra-se organizado em duas diferentes partes: a primeira compreende a revisão de literatura em relação ao tema proposto e, a segunda é composta pelo trabalho de campo in loco. No trabalho de campo, foram coletados dados estatísticos e demais materiais e informações pertinentes ao estudo, também foram realizadas entrevistas com viticultores e visitas aos municípios, e às propriedades agrícolas para verificar a dinâmica agrária familiar presente nosdois municípios.

\section{Mapa 1: localização da área de estudo}

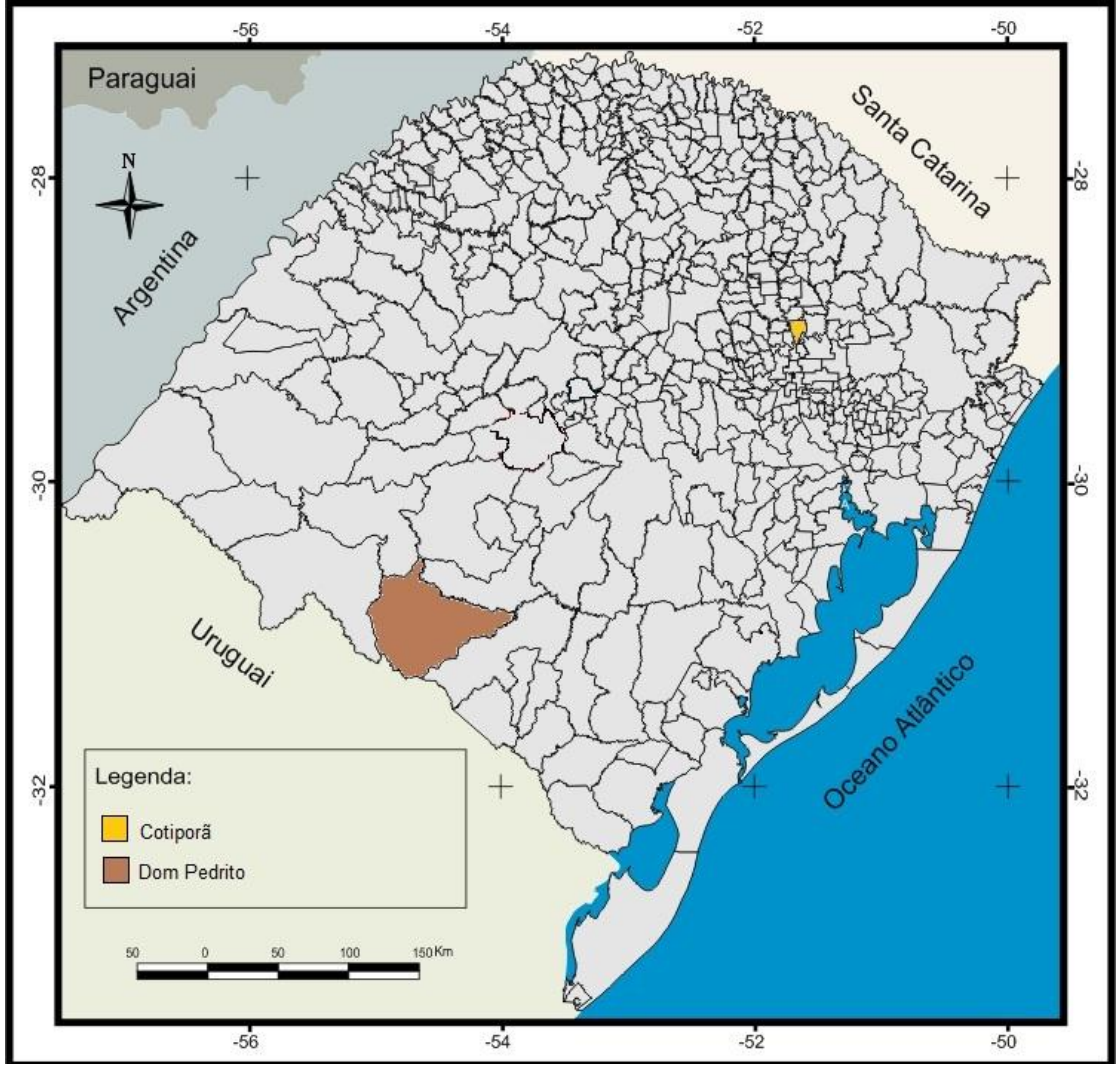

Fonte: IBGE (2010), adaptado por Vanessa Manfio, 2017.

Para0nde!?, Porto Alegre, v.11, n.1, p.37-44, 2019. http://seer.ufrgs.br/paraonde

Edição Especial: "Geografia e transformações socioespaciais: dinâmicas agrárias e políticas do desenvolvimento regional" 
0 texto do trabalho encontra-se estruturado em três partes que irão conduzir as considerações finais: a primeira parte apresenta uma discussão sobre agricultura familiar e a produção de uva e o processamento da fruta, a segunda, uma abordagem sobre a vitivinicultura familiar de Cotiporã e na sequência a análise sobre a vitivinicultura desenvolvida em pequenas propriedades rurais no interior do município de Dom Pedrito.

\section{A Agricultura Familiar e a Vitivinicultura}

A agricultura familiar é entendida como aquela em que a gestão, a propriedade e a maior parte do trabalho vêm de indivíduos que mantêm entre si laços de sangue ou de casamento e vivem na mesma terra (ABRAMOVAY, 1997). Nos últimos anos, a agricultura familiar tem estado mais presente nas pesquisas acadêmicas e políticas públicas, constituindo-se numa categoria importante no meio rural como menciona Niederle, Verardi Filho e Conterato (2014, p.15):

Ao mesmo tempo, à medida que a agricultura familiar afirmava-se e conquistava espaço enquanto segmento produtivo no meio rural, inúmeros pesquisadores começaram a dedicar esforços para analisar o lugar destes produtores nos modernos mercados agrícolas e as consequências da reestruturação do sistema agroalimentar em um contexto de globalização.

Assim, surgem práticas modernas e inovadoras na agricultura familiar voltadas para agradar e estimular o mercado, além de diversificar a produção agrícola e demais atividades econômicas presentes nas propriedades rurais, como a produção de alimentos orgânicos, práticas turísticas, entre outras. Segundo Assumpção (2008), o agricultor familiar, sem deixar de lado seus valores de cooperação e solidariedade, e sua cultura têm buscado novas maneiras de inserção de seus produtos no mercado, visando uma maior apropriação do valor agregado para buscar uma maior participação do processo econômico.

Nota-se que em tempos não muito distantes no Brasil, essa prática era apenas uma produção alternativa e ocupava poucas terras, no entanto, hoje, ela vem trazendo e proporcionando uma diversificação nas atividades agropecuárias, que são necessárias para o desenvolvimento rural e para a permanência de várias famílias no campo (SIMÃO; BANDEIRA, 2014). Deste modo, a agricultura familiar é de extrema importância para alimentação da população e economia brasileira, pois se concentra na maioria das áreas agrícolas do país. Conforme Manfio (2015, p.185), "A agricultura familiar é importante no Brasil, sendo responsável por grande parte da produção de alimentos e da distribuição fundiária igualitária".

Neste contexto, são variados os produtos cultivados pela agricultura familiar, sendo a videira um dos principais exemplos presentes no Rio Grande do Sul, especialmente em áreas de colonização italiana, associada à cultura e a necessidade do consumo de vinho, que é parte identitária deste povo e acompanha os pratos das principais refeições diárias dos descendentes dessa etnia. Para Duarte, Salamoni e Costa (2011), na região de colonização italiana da Serra Gaúcha os ensinamentos sobre a elaboração do vinho eram passados de geração em geração, sendo o vinho produzido pelas famílias italianas de maneira bastante artesanal, onde após a colheita das uvas, fabricavam o vinho em cantinas, localizadas nos porões das casas de moradia, para consumo próprio. Posteriormente, os colonos com o interesse em ampliar a renda familiar avançaram a produção de vinhos antes restrita ao consumo familiar e passaram a comercializar a bebida com outros produtores rurais que não o produziam (DUARTE; SALAMONI; COSTA, 2011).

Este é o caso da região da Serra Gaúcha, cuja produção de vinhos está atrelada ao colono italiano e depois aos seus descendentes que inicialmente produziam o vinho para o consumo próprio e num segundo momento investiram nesta atividade alcançando umeixo econômico regional, transformando com o passar dos anos a região no pólo vitivinícola mais importante do país. Estas raízes culturais vitivinícolas estão presentes na agricultura familiar da região, onde agricultores

Para0nde!?, Porto Alegre, v.11, n.1, p.37-44, 2019. http://seer.ufrgs.br/paraonde

Edição Especial: "Geografia e transformações socioespaciais: dinâmicas agrárias e políticas do desenvolvimento regional" 
familiares cultivam videiras e produzem vinhos artesanalmente e/ou estão inseridos numa nova lógica mercadológica de produção de uvas e sucos orgânicos como, por exemplo, os viticultores do município de Cotiporã.

Porém, Franket al. (2014) apontam que a vitivinicultura pode ser uma opção de produção principal ou complementar para os agricultores, a fim de aumentar os lucros de sua produção agrícola. "A diversificação da produção agropecuária também fortalece a agricultura familiar" (FRANK et al., 2014, p. 37). Assim, como acontece em Dom Pedrito, onde a vitivinicultura surge como um novo mecanismo de diversificação agrícola e incremento de renda ao produtor que passa a se beneficiar a partir de políticas públicas e inserir-se num contexto de inovação rural.

A vitivinicultura tem experimentado forte dinâmica no desenvolvimento de novas regiões produtivas, sobretudo, para estabelecer fatores de sustentabilidade econômica, ambiental e social às pequenas propriedades de agricultura familiar (MELLO et al., 2007). Com isso, a agricultura familiar pode ter como mecanismo de desenvolvimento e promoção de renda a vitivinicultura, associando a cultura local, as ações familiares e a visibilidade sustentável. Dessa forma, a cadeia produtiva de vinhos e suco de uva abarca os pequenos produtores rurais, que com tradição ou não, passam a investir e apostar no setor vitivinícola.

\section{A Vitivinicultura Orgânica Praticada em Cotiporã}

A produção de uva em Cotiporã é um cultivo bastante tradicional no município, sendo o principal produto agrícola cultivado pelos agricultores. A cultura da uva é um legado da colonização italiana que deu origem ao local onde hoje se localiza o município. 0 trabalho nos vinhedos, em sua maior parte, é realizado por descendentes de colonos italianos, que ali se instalaram e são originalmente oriundos da Região do Vêneto localizada no nordeste da Itália. Os parreirais cotiporanenses, assim como toda a vitivinicultura da região da Serra Gaúcha foi fortemente influenciada e difundida no lugara partir da chegada dos primeiros colonos italianos, que vieram colonizar a região, "[...] com a imigração italiana a atividade vitivinícola teve um incremento significativo [...]" (Souza, 2005, p.17).

A maior parte da uva cultivada no município é realizada no sistema convencional de produção, que faz a utilização de produtos químicos e sintéticos (tóxicos) e, demais pacotes tecnológicos fornecidos pela indústria para combater pragas, doenças e ervas daninhas que atacam as videiras. 0 maquinário agrícola, por sua vez, é pouco utilizado no município, bem como, em toda a região da Serra Gaúcha em virtude do relevo ser bastante acidentado, o que dificulta e/ou impede a utilização. Todavia, um grupo composto por treze agricultores locais fez a opção por converter seus vinhedos do sistema convencional para a produção orgânica.

Os viticultores que aderiram à produção orgânica fundaram a Associação dos Agricultores Ecologistas de Cotiporã (ECOVÊNETO), que mantém parceria com a Organização Não Governamental (ONG), Centro Ecológico de Ipê - Núcleo Serra, entidade colaborativa da Rede Ecovida de Agroecologia, que é a instituição que fornece capacitações aos agricultores, bem como, certifica a uva produzida pelos produtores rurais. No município os principais parceiros e agentes que estimulam a viticultura sustentável são: a Empresa de Assistência Técnica e Extensão Rural do Estado do Rio Grande do Sul (EMATER) - escritório de Cotiporã, a Prefeitura Municipal, a própria ECOVÊNETO e a Cooperativa de Sucos Monte Vêneto.

É importante mencionar que as principais variedades de uvas cultivadas nesse sistema orgânico desenvolvido no espaço rural de Cotiporã são de uvas tipo: Bordô, Rúbia e Concord, destinadas para produção de suco, enquanto a variedade Niágara Branca é destinada para o vinho de mesa, entre outras cultivares que são utilizadas como uvas de mesa (PIEROZAN, 2017).

A comercialização da uva orgânica atinge uma escala de âmbito local-regional. A maior parte da fruta produzida é comercializada no próprio município para consumo in natura nas casas dos agricultores e outra parcela que permanece no município é transformada em suco de uva orgânico pela Cooperativa de Sucos Monte Vêneto, que tem os agricultores orgânicos como parceiros. Todavia, o restante da safra tem como destino as vinícolas localizadas nos municípios vizinhos de Bento Gonçalves e Veranópolis.

ParaOnde!?, Porto Alegre, v.11, n.1, p.37-44, 2019. http://seer.ufrgs.br/paraonde

Edição Especial: "Geografia e transformações socioespaciais: dinâmicas agrárias e políticas do desenvolvimento regional" 
A viticultura desenvolvida em Cotiporã é caracterizada como sendo praticada em pequenas propriedades agrícolas de mão de obra familiar. 0 trabalho nos vinhedos em sua maior parte é uma atividade de herança familiar, que passa de pai para filho. É comum encontrar nos vinhedos diferentes gerações de familiares como, por exemplo, pai, filhos, tios e avós trabalhando em conjunto na mesma propriedade e compartilhando o mesmo ambiente de trabalho.

A produção de uva realizada pelos agricultores que fazem parte da ECOVÊNETO se utiliza de técnicas que:

[...] envolvem práticas sustentáveis no manejo do solo, combate ás pragas e controle de doenças a partir de produtos naturais desenvolvidos pelos próprios produtores rurais como, por exemplo, a calda bordalesa, o adubo bokashi, a poda da videira a partir do calendário lunar, além de cuidados adicionais no momento da colheita da fruta (PIEROZAN; MEDEIROS, 2017, p.484).

Todos esses produtos e demais conjunto de práticas são aplicados e aperfeiçoados pelos próprios agricultores, a partir da experimentação em suas propriedades rurais e nos seus vinhedos tomando como base sempre as características particulares de cada unidade de produção agrícola.

\section{Dinâmicas da Vitivinicultura em Pequenas Propriedades Rurais de Dom Pedrito}

O município de Dom Pedrito tem sua base econômica voltada para a agropecuária, inicialmente com a pecuária extensiva e, atualmente com a lavoura empresarial e a pecuária intensiva. No entanto, nos últimos anos, a vitivinicultura vem se desenvolvendo consideravelmente na região, juntamente com a expansão das atividades de fruticultura, silvicultura e produção de oliveiras, devido uma estratégia voltada para a diversificação das atividades agrícolas.

No que tange a produção de uvas e vinhos finos, ela surge na região através de vários estudos que identificaram condições edafoclimáticas bastante favoráveis para o cultivo de videiras. Segundo Zocche, (2009, p.9) várias "[...] pesquisas agroclimáticas foram realizadas e demonstraram que a Metade Sul do Rio Grande do Sul possui potencial climático e edafológico para tornar-se um grande pólo vitivinícola brasileiro".

No município de Dom Pedrito, a viticultura teve início com o cultivo dos vinhedos Camponogara na década de 1990. Posteriormente, foi impulsionada com a percepção da promissão da atividade no município, associada ao desenvolvimento de diversos seminários sobre a temática na região, além de investimentos advindos por intermédio do Banco Nacional de Desenvolvimento Econômico e Social (BNDES), com a oferta de uma linha de financiamento específica para o cultivo de uvas, desta forma, novos agricultores passaram, então, a apostar na vitivinicultura (WERKA et al., 2013).

Além disso, diferentes produtores rurais e empresários com capital financeiro disponível também resolveram investir e apostar nas possibilidades que começaram a despontar no setor vitivinícola. Nesse sentido, ganhou impulso na região principalmente a vitivinicultura comercial destinada a produção de vinhos finos voltada para o mercado nacional e internacional com as empresas: Irmãos Camponogara, Dom Pedrito Vinhos Nobres, Guatambu - Estância do Vinho e Dunamis (PIEROZAN; MANFIO; MEDEIROS, 2016).

Diante da visibilidade que a região está adquirindo em virtude dos ótimos vinhos produzidos na Campanha pequenos produtores rurais têm buscado produzir vinhos e sucos de uva no município, estes recebem apoio de diversas instituições como a EMATER, Secretaria de Agricultura, Pecuária e Irrigação de Dom Pedrito e através de diferentes políticas públicas. Entre estas políticas estão o Programa de Agroindústrias e o programa Quintais Orgânicos de Frutas

\footnotetext{
${ }^{1}$ Esse projeto da Embrapa Clima temperado foi escolhido para participar da Plataforma de Boas Práticas para o Desenvolvimento Sustentável, que faz parte do programa de cooperação com a Organização das Nações Unidas para a Alimentação e a Agricultura FAO (EMBRAPA CLIMA TEMPERADO, 2016).
}

ParaOnde!?, Porto Alegre, v.11, n.1, p.37-44, 2019. http://seer.ufrgs.br/paraonde

Edição Especial: “Geografia e transformações socioespaciais: dinâmicas agrárias e políticas do desenvolvimento regional” 
Segundo Ministério da Agricultura (2009), o Programa de Agroindústrias visa apoiar a inclusão dos agricultores familiares no processo de agroindustrialização e comercialização da sua produção, de modo a agregar valor ao produto, gerar renda e novas oportunidades de trabalho no meio rural, sendo um programa nacional destinado a agricultura familiar.

Em Dom Pedrito, a participação dos produtores rurais no programa das agroindústrias teve início no ano de 2013 e conta atualmente com 19 empresas formalizadas que fabricam produtos derivados do leite (queijo e iogurte), suco de laranja, suco de uva e vinho artesanal, morango e geleias, entre outros produtos agrícolas.

Já o programa Quintais Orgânicos de Frutas privilegia a produção sustentável, onde cada quintal é constituído por cinco plantas de 18 espécies de frutas; as diferentes espécies de frutas incluem: pêssego, figo, laranja, amora-preta, cereja-do-rio-grande, araçá, goiaba, caqui, pitanga, romã, tangerina, limão, guabiju, araticum, uvaia, videira (Figura 1), jabuticaba e guabiroba (EMBRAPA CLIMA TEMPERADO, 2016).

Figura 1: videiras da agricultura familiar

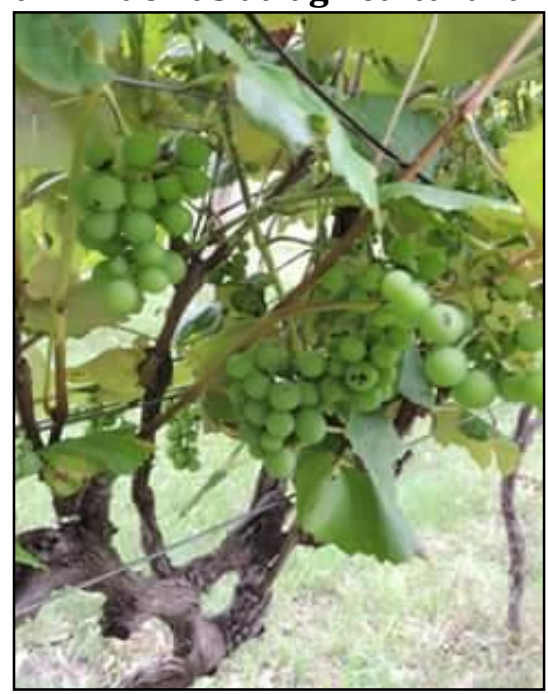

Fonte: Prefeitura municipal de Dom Pedrito.

Autor: Marcelo Beskow, 2015.

Os agricultores familiares que participam do programa Quintais Orgânicos de Frutas, com parte de sua produção de frutas produzem sucos, geleias, vinho artesanal, licores entre outros produtos, além de também realizarem a venda da fruta para o consumo in natura. Somando-se as frutas, têm agricultores que também cultivam flores e aproveitam a oportunidade para comercializá-las no mesmo espaço que os demais produtos oriundos da produção familiar. Existindo agricultores que estão participando simultaneamente dos dois projetos: o das Agroindústrias e o dos Quintais Orgânicos de Frutas.

No que diz respeito ao vinho, em Dom Pedrito, existem aproximadamente 11 pequenos produtores rurais de uva e vinho, alguns produzem uvas no sistema convencional e outros no sistema orgânico, existindo um crescente interesse por parte de outros agricultores em cultivar vinhedos e buscarem se inserir na cadeia da vitivinicultura (LOPES, 2016).

Os produtores de vinhos orgânicos do município seguem as orientações da Vinícola Salton para a produção de uva orgânica. Para Pierozan, Manfio e Medeiros (2016), na vitivinicultura orgânica são cultivadas uvas: Cabernet Sauvignon, Tannat e Merlot, além de uvas de outras variedades destinadas para o consumo in natura. Dentre as práticas que visam causar uma menor agressão possível ao ambiente temos a utilização da calda de bordalesa (fertilizante foliar composto por cobre, enxofre e cálcio), o bokashi (composto fermentado para a melhoria da qualidade do solo) e a limpeza dos vinhedos que, são feitas por meio de roçadas, não são utilizados herbicidas para controlar o avanço e

Para0nde!?, Porto Alegre, v.11, n.1, p.37-44, 2019. http://seer.ufrgs.br/paraonde

Edição Especial: “Geografia e transformações socioespaciais: dinâmicas agrárias e políticas do desenvolvimento regional” 
o crescimento de ervas daninhas, entre os vinhedos.

Estes agricultores familiares são incentivados pela Secretaria de Agricultura, Pecuária e Irrigação de Dom Pedrito que, juntamente com outras instituições, que atuam de modo colaborativo, organizam uma feira municipal que acontece semanalmente, às sextas-feiras, na praça matriz da cidade, titulada de Projeto Feira Livre de Dom Pedrito, onde os diferentes agricultores comercializam os produtos oriundos destes dois projetos e da agricultura familiar, (Figura 2 e Figura 3). Dentre os produtos comercializados na feira destacamos como exemplo: vinhos, queijos, geleias, ovos, frutas, verduras, legumes e hortaliças.

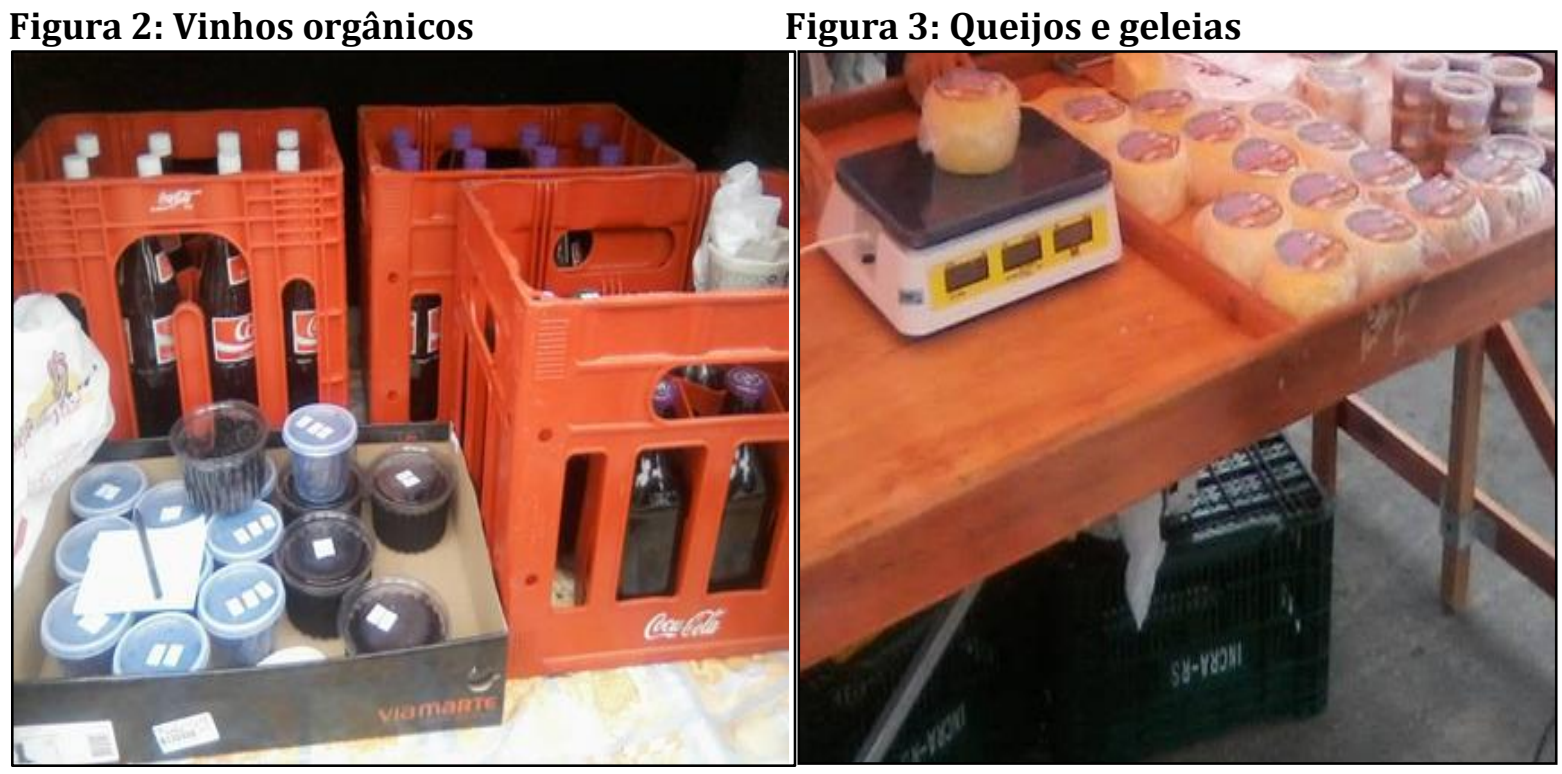

Fonte: Prefeitura municipal de Dom Pedrito. Fonte: Prefeitura municipal de Dom Pedrito. Autor: Jorge O. Lopes, $2015 . \quad$ Autor: Jorge O. Lopes, 2015.

Algumas feiras também foram montadas na Universidade Federal do Pampa (UNIPAMPA), Campus Dom Pedrito, para a comercialização dos produtos agroindustriais locais. Estas feiras são um mecanismo que mobiliza bastante força para contribuir com o desenvolvimento rural local e visam auxiliar os pequenos produtores rurais, especialmente os que se dedicam ao cultivo da uva e à produção de vinho.

Além das feiras, a comercialização da uva e dos produtos orgânicos acontece localmente, com vizinhos e visitantes, principalmente nas residências dos produtores, onde a produção artesanal do vinho e demais produtos acontece (MANFIO, 2018).

Dessa forma, a produção de uva e vinho orgânico em Dom Pedrito constitui-se numa realidade significativa para o desenvolvimento rural e a diversificação da produção familiar, aproveitando a expansão da cadeia produtiva da uva que vem se articulando territorialmente na região. Acredita-se que uma parceria entre os produtores rurais de orgânicos, como uma associação ou cooperativa seria uma ferramenta importante para alavancar ainda mais a produção de uva e vinho familiar no muncípio de Dom Pedrito, assim como já acontece no município de Cotiporã.

\section{Considerações Finais}

A vitivinicultura orgânica está proporcionando aos agricultores familiares que estão buscando se inserir e aos que já estão há mais tempo e pretendem se consolidar nesse tipo de produção, novas perspectivas para o rural e principalmente para os agricultores que fazem parte da agricultura familiar. Tanto em Cotiporã, que possui tradição na produção de uvas e a região já apresenta uma vitivinicultura consolidada, quanto Dom Pedrito, onde as videiras ainda são vistas como novidade para muitos, a produção orgânica desperta curiosidade, mobiliza o interesse e o desejo dos

Para0nde!?, Porto Alegre, v.11, n.1, p.37-44, 2019. http://seer.ufrgs.br/paraonde

Edição Especial: "Geografia e transformações socioespaciais: dinâmicas agrárias e políticas do desenvolvimento regional" 
agricultores em partir para uma produção diferenciada, que busque o equilíbrio entre a agricultura, o ambiente e o produtor rural.

No município de Cotiporã, os viticultores que migraram do sistema convencional para o orgânico relataram que as condições de trabalho e de saúde do agricultor melhoraram significativamente com o abandono dos agrotóxicos e demais produtos químicos industrializados antes utilizados nas propriedades e nos cultivos. 0 conhecimento prático, adquirido com a experiência acumulada ao longo dos anos de trabalho nos parreirais passou a ser valorizado com a produção orgânica, antes o protagonismo pertencia aos produtos químicos, aos agrotóxicos e demais insumos industriais, que eram aplicados nas parreiras, agora ganha valor o trabalho realizado pelo agricultor.

Em Dom Pedrito, a produção de uvas orgânicas ainda é uma atividade agrícola bastante recente, e está atraindo diferentes adeptos, que vislumbram na viticultura uma possibilidade em diversificar a produção nas propriedades, bem como, explorar as potencialidades, que a região dispõe como o clima e solo favorável a instalação de vinhedos. Os incentivos institucionais são um dos grandes agentes estimulantes a adesão a essa nova forma de se produzir alimentos mais saudáveis em curso no município.

Os principais ganhos verificados na produção de uva orgânica foram a valorização do produto no momento da comercialização, a independência dos agricultores em relação as vinícolas que dominam e verticalizam o setor, a valorização do trabalho familiar aliado a permanência das famílias no meio rural,preservação do ambiente com menor impacto nos recursos naturais disponíveis nas propriedades dos viticultores.

\section{Referências}

ABRAMOVAY, R. O Futuro das regiões rurais. Porto Alegre: Editora UFRGS, 1997.

ASSUMPÇÃO, R. de. Novas oportunidades para a agricultura familiar: metodologia de organização do negócio agrícola. Revista Tecnológica \& Inovação Agropecuária. Agência Paulista de Tecnologia dos Agronegócios. v.1, n.2, 2008.

DUARTE, T. S.; SALAMONI, G.; COSTA, A. J. V. Turismo no Espaço Rural, Práticas Locais e Imigração Italiana: O Caminho Colonial do Vinho. Pelotas/RS, 2011.

EMBRAPA CLIMA TEMPERADO. Quintais Orgânicos de frutas. Disponível em:<https://www.embrapa.br/clima-temperado/busca-de-produtos-processos-e-servicos/-

/produto-servico/1418/quintais-organicos-de-frutas>. Acesso em: 20 de maio de 2017.

FEDERAÇÃO DAS COOPERATIVAS VINÍCOLAS DO RIO GRANDE DO SUL. Histórico. Disponível em: <http://www.fecovinho.coop.br/secao.php?pagina=1>. Acesso em: 22 de março de 2019.

FRANK, L. et al. Alternativas de agregação de valor para a produção familiar: Cooperativa Amperence dos Produtores de Vinho (Coopevi). COLÓQUIO - Revista do Desenvolvimento Regional. Taquara/RS - v. 11, n. 2, p. 31-43, jul./dez. $2014 . \quad$ Disponível em: <https://seer.faccat.br/index.php/coloquio/article/download/150/13>. Acesso em: 12 de janeiro de 2017.

INSTITUTO BRASILEIRO DE GEOGRAFIA E ESTATÍSTICA. Divisão Territorial do Brasil e Limites Territoriais. Acesso em: 17 de maio de 2017.

MANFIO, V. Agricultura familiar no município de Nova Palma-RS: uma análise sobre as dinâmicas e potencialidades. Geographia Meridionalis. Pelotas, v. 01, n. 02, p. 183-201, Jan-Dez/2015.

MANFIO, V. Vitivinicultura e associativismo: a dinâmica da Associação Vinhos da Campanha na formação de um território no Rio Grande do Sul, Brasil. 2018. 254f. Tese (Doutorado em Geografia) - Universidade Federal do Rio Grande do Sul, Porto Alegre, 2018.

MELLO, L. M. R. de. et al. Evolução e dinâmica da produção de uva no Brasil no período de 1975 a 2003. Bento Gonçalves: Embrapa Uva e vinho, 2007.

Para0nde!?, Porto Alegre, v.11, n.1, p.37-44, 2019. http://seer.ufrgs.br/paraonde

Edição Especial: "Geografia e transformações socioespaciais: dinâmicas agrárias e políticas do desenvolvimento regional" 
MINISTÉRIO NACIONAL DA AGRICULTURA. Sistema de agroindústria familiar. Disponível em: <http://www.mda.gov.br/sitemda/secretaria/saf-agro/sobre-o-programa>. Acesso em: 12 de janeiro de 2017.

NIEDERLE, P. A.; VERARDI FIALHO, M. A.; CONTERATO, M. A. A pesquisa sobre agricultura familiar no Brasil - aprendizagens, esquecimentos e novidade. Rev. Economia Sociologia Rural, Brasília. vol. 52 supl.1, 2014.

PIEROZAN, V. L.; MANFIO, V.; MEDEIROS, R. M. V. A viticultura orgânica no Rio Grande do Sul: o caso da transformação do espaço agrário de Cotiporã e Dom Pedrito. In: Encontro Nacional de Geografia Agrária, ENGA, XXIII, 2016, São Cristóvão. Anais... São Cristóvão: UFS, 9 a 13 de Nov. de 2016. CDROM.

PIEROZAN, V. L.; MEDEIROS, R. M. V. A produção de uvas orgânicas como proposta para uma nova ruralidade: o caso da experiência dos viticultores pertencentes a Associação dos Agricultores Ecologistas de Cotiporã - ECOVÊNETO. In: Encontro Nacional de Grupos de Pesquisa, ENGRUP, IX, 2017, Porto Alegre. Anais... Porto Alegre, UFRGS, 15 a 17 de mar. de 2017. Disponível em: <http://neagufrgs.wixsite.com/engrup2016/anais>. Acesso em: 28 de maio de 2017.

PIEROZAN, V. L. 0 território da vitivinicultura orgânica no território da vitivinicultura da "Serra Gaúcha": o caso dos viticultores de Cotiporã. 2017. 132f. Dissertação (Mestrado em Geografia) - Universidade Federal do Rio Grande do Sul, Porto Alegre, 2017.

PREFEITURA MUNICIPAL DE DOM PEDRITO. Secretaria de Agricultura, Pecuária e Irrigação. Disponível em: <http://dompedrito.rs.gov.br/secretariaView/7_Secretaria-de-Agricultura-Pecuariae-Irrigacao.html>. Acesso em: 31 de março de 2019.

SIMÃO, A. G.; BANDEIRA, A. 0 cooperativismo como alternativa para o atingimento da sustentabilidade.

Disponível

em:

<http://www.unifae.br/publicaçoes/pdf/sustentabilidade/angelo_arnaldo_cooperativas.pdf>.

Acesso em: 5 de abril de 2017.

SOUZA, F. A. Mudanças Promovidas no Setor Vitivinícola do Rio Grande do Sul Pela Inserção de Profissionais Especializados nas Áreas de Viticultura e Enologia. 2005. 159f. Dissertação (Mestrado em Ciências) - Universidade Federal do Rio de Janeiro. Rio de Janeiro, 2005.

WERKA, C. etal. Panorama da vitivinicultura em Dom Pedrito/RS. Cadernos de Agroecologia. V. 8, n.2, $2013 . \quad$ Disponível em: <http://www.abaagroecologia.org.br/revistas/index.php/cad/issue/view/72>. Acesso em: 12 de maio de 2017.

OCCHE, R. G. S. Potencial enológico de uvas Tannat, Cabernet Sauvignon e Merlot produzidas no município de Bagé - RS. 2009. 113f. Tese (Doutorado em ciências) - Universidade Federal de Pelotas. Pelotas, 2009.

Para0nde!?, Porto Alegre, v.11, n.1, p.37-44, 2019. http://seer.ufrgs.br/paraonde

Edição Especial: "Geografia e transformações socioespaciais: dinâmicas agrárias e políticas do desenvolvimento regional" 